\title{
Research on the Development of Social Organization in Yunnan Cross-Border Minority Concentrated Region
}

\author{
Ma Guofang \\ School of Public Administration, Yunnan University of Finance and Economics,, \\ Yunnan , P. R. China, 650221 \\ (314200361@qq.com)
}

\begin{abstract}
Social organization is a sociological concept, defined as a pattern of relationships between and among individuals and groups. There are a large number of mass organizations in China, which carry out their activities independently in accordance with the Constitution and the law.The sixteen session of the six plenary session of the party first put forward the concept of social organization and required binging into play the role of providing service, reflecting appeal, regulating behavior of social organization and strengthening the function of serving society of social organization. The paper investigates the current situation and role of social organizations in Yunnan cross-border minority concentrated region, analyses the special background and characteristics confronting with at present, so as to put forward some advices for the development of social organizations in Yunnan cross-border minority concentrated region.
\end{abstract}

Keywords: Yunnan, Cross-Border Minority Concentrated Region, Social Organizations

\section{Introduction}

The Central government put forward the concept of social organization in the Sixth Plenary Session of the Sixteenth Central Committee and required to bring into the play of social organization in proving service, appealing and regulating behavior and to strengthen the social organizations' function of serving society. so how to promote the healthy development of social organization has been an important and urgent task for all levels of government. However, as it should be a rational action for all levels of government to promote the healthy development of social organizations, our government must summarize the experiences and reflect rationally about the present situation and development of social organization in China.

This paper aims to explore the basic situation of social organizations in Yunnan cross-border minority concentrated region, investigates the current situation and role of social organizations in Yunnan crossborder minority concentrated region, and analyses the special background and characteristics confronting with at present, so as to put forward some advices for the development of social organizations in Yunnan cross-border minority concentrated region.

\section{The Role of Social Organizations in Cross- Border Minority Concentrated Region}

2.1 Promoting the economical development in minority concentrated region

Firstly, the government should promote the development of local special industries and make social organizations serve for the local economical development. During the process of economic marketization and social diversity, the social organizations have played an important role in crossborder minority concentrated region. The social organizations in cross-border minority concentrated region have adopted various ways and mechanism to make use of resource for purpose of well and justify, expand the services sector and meet the increasing needs of the masses of the people according to market development. 
Secondly, the local government should integrate market resource, regulate and strengthen the healthy development of private businesses and participate in the economic cooperation and communications between countries and regions. The social organizations in cross-border minority concentrated region also have played a positive role in the regulation of he healthy development of private businesses. The rise and development of social organizations in cross-border minority concentrated region will promote the economic cooperation and communications between China and neighboring countries and improve the opening up and economic development.

Lastly, the rise and development of social organizations in cross-border minority concentrated region will help the strengthening of enterprise competitiveness. The social organizations in crossborder minority concentrated region have played an important role in avoiding the disorder competition among enterprises and the improving of enterprise competitiveness.

\subsection{Developing the culture in minority} concentrated region

The rise and development of social organizations in cross-border minority concentrated region will help the protection of ethnic culture and religious culture. The ethnic culture in Yunnan is the important reflection of Yunnan spirit and cultural heritage, so it should be paid more attention on the protection of ethnic culture. The social organizations in crossborder minority concentrated region will be an important and major main force during the protection of Yunnan unique ethnic culture and religious culture. Those social organizations will promote the development and transmission of ethnic culture through holding a series of national festival of traditional ceremony, collecting and wring of ethnic culture and seeking and supporting research talents of ethnic culture.

The local government should improve the culture level of the popular masses, promote the communication of ethnic culture between China and neighboring countries. The social organizations in cross-border minority concentrated region will make up the limit of educational resources and settle some practical issues such as the children's difficulty of education. Such cooperation between China and neighboring countries not only relieve the limit of national educational resources, but also promote the ethnic culture communication and national unity. At the same time, the social organizations in crossborder minority concentrated region will also enrich the cultural life of the people masses and guide substantial other social organizations to development healthily.

\subsection{Conducting the governmental functions and} playing a role of bridge and tie

Many social organizations have participate in the development of infrastructure in cross-border minority concentrated region especially in construction. In a words, the social organizations in cross-border minority concentrated region have made up the insufficiency of governmental public service and played active role in every aspect of economy, politics, culture and social life.

At the same time, the social organizations in crossborder minority concentrated region have participate in the decision-making of local government. Some social organizations are developed and supported by local government and also provide some valuable information and advices for the local economical development. some social organizations also will 
hold some activities to maintain peasants' rights and benefits, so as to influence the governmental act.

\subsection{Maintaining the stability in border areas and educating ethnic talents}

The social organizations in cross-border minority concentrated region is an important force in the construction and development of the harmonious society through maintaining the national unity, strengthening national cohesion and promoting national solidarity and common prosperity. Some social organizations also played an important role in aging problem such as communication, cultural activities, sports activities, sightseeing and so on, which promotes the development of cause for the aging population and new rural construction. Some social organizations will promote the harmonious relationships between cross-border ethnic groups by communication and cooperation.

The social organizations in cross-border minority concentrated region have played an important role in the development of local education, talent cultivation, employment promotion and so on. For example, a lot of non-profit organization in cross-border minority concentrated region have made substantial contribution for the pre-school education in Malipo city and some art professional training colleges also have developed the traditional dancing culture of Wa nationality in Lingcang city.

\section{The Unique Characteristics of Social Organizations in Yunnan}

At present, the social organizations in cross-border minority concentrated region also confront with some special difficulties during their development. of course these social organizations in cross-border minority concentrated region have their own unique characteristics which are different from other social organizations in southeastern areas of China.

\subsection{The special background for the cultivation and development of social organizations}

During the development of the social organizations in cross-border minority concentrated region, the independent social forces and economic and cultural environment also played a significant role in the local region. Due to the differences between regions with different economic foundation, economic system, development pattern and ethnic culture, the social organizations also confront with different economic and social environment. The objective environment results in a series of difficulties such as system and culture for social organization to handle and adapt in. Since opening up, the economic and social development have gained substantial result in crossborder minority concentrated region, and the level of life of cross-border ethnic groups also improved significantly. However, there are a series of issues in cross-border minority concentrated region such as poverty, environment deterioration, ethnic conflicts, religious issue, border security, educational issue, population issue and so on. These issues result in the relative low modernization, and the complexity of various issues. So the central government should promote the western development significantly, fully respect, utilize and development the emotional ties and greatly improve the development of economic and social culture in cross-border minority concentrated region, so as to strengthen the force and influence of social organizations in cross-border minority concentrated region.

3.2.The characteristics of social organizations in Yunnan 
The social organizations in cross-border minority concentrated region have diversity, but they must be suitable to the development of modernization in China, which also become the necessity of develop the social organizations in cross-border minority concentrated region. However, the social organizations in Yunnan have some unique characteristics which are deferent from others in southeastern areas of China.

Firstly, the development of the social organizations in cross-border minority concentrated region is limited by the socialist democracy of ethnic villages. Due to the complex historical process, diversity of traditional culture, relative low level of economic development, natural environment and social environment, the socialist democracy of ethnic villages has its own unique characteristics such as imperfect power supervisee, management functions, social service and so on.

Secondly, the low level of civil society will also influence the development of social organizations in cross-border minority concentrated region. The consciousness of citizenship which is the fundamental foundation for the development of social organizations is related with the citizenship awareness and historical culture. However, as a relative low region in China, Yunnan province with undeveloped economy and culture and slow process of citizenship awareness is not compete with the historical and awareness conditions.

Thirdly, the negative aspects of diversified culture will influence the development of the social organizations in cross-border minority concentrated region. Historically, various cultures communicate and form the unrecorded traditions of a people, namely Chinese culture. But there are some negative aspects in the ethnic culture such as conserved mind, enclosing mind, sense of inferiority, satisfied awareness, and regional identity and so on. These negative aspects of ethnic culture have influence the development of the social organizations in crossborder minority concentrated region.

Lastly, there are substantial grass-root social organizations in cross-border minority concentrated region, especially in Yunnan. As a multi-ethnic, multi-culture province, there are lots of nongovernmental organizations which are not registered in governmental departments. These grass-root social organizations which originated from ethnic culture and frontier culture have some unique characteristics with historic inheritress and real life. At the same time, the members of these grass-root nongovernmental organizations participate in these organizations with strong religion and nationalities. As far as some social organizations in the ethnic villages concerned, the characteristics of religion is very clear and strong during the origin and development of the social organizations in crossborder minority concentrated region. Especially some ethnic groups such as Dai, Wa, Jiruo believe in some kinds of religions, so their awareness of participation in politics is very strong.

\section{Conclusion}

In order to promote the healthy development of the social organizations in cross-border minority concentrated region, the author think that all levels of government should adopt some suitable measure to guide and encourage the rational development in the multi - ethnic frontier. Specifically, some measures should be adopted or established $n$ cross-border minority concentrated region.

Firstly, the legal system must be established to guarantee the nice development of the social organizations in cross-border minority concentrated 
region. The central government or local government should establish some changing or compensatory local decrees, autonomous decrees and special decrees, and rules. At the same time, the ethnic autonomous areas should effectively exercise selfgovernment according to the law, local decrees, autonomous decrees and special decrees, and rules, so as to guarantee the rights and benefits of the social organizations.

Secondly, the registration system of social organization should be improved and the purchasing of social organizations' service should be encouraged. The local government in Yunnan should realize the reform of management system and adopt simple single-registration system.

Thirdly, the local government also should transform their own role during the guidance of social organization. The local government should regard the social organizations as the equal management forces and establish long-term friendly and cooperative partnership and work together to promote the social progress.

Lastly, the local government should strengthen the supervision on the social organizations in crossborder minority concentrated region. The supervision on the social organizations should be promote from the following aspects, such as establishing unity registration system, strong guidance, setting up and improving the evaluation system and check up system.

\section{References}

(1) Li, Qingwei. (2009) Research on The Social Responsibility of Non-Profit Organizations. Political Science and Law , 2, 64-70

(2) Wang, Jianjun. (2012). The Issues and Countermeasures for The Cultivation and
Development of Social Organizations in China. Xinhua Digest, 16,17-19

(3) Wang, Zhenghai, Song Gaofeng. (2011). The Influencing Factor and The Prophylactic Measure of Local Social Organization. Study Forum, 8, 103

(4) Xu, Jianbang. (2007). The Social Responsibility and Measurement of Non-Profit Organizations, Theory Horizon, 11, 87-92

(5) Yan, Kegao. (2006). The Social Responsibility and Construction of Harmonious Society of Non-Profit Organizations. Exploration and Free Views, 9, 29-31

(6) Zhang, Jian. (2011). The system and Meanings of American Frontier Governance Policy. Journal of Yunnan School of Administration, 5, 162 